\title{
Retrograde amnesia after traumatic injury of the fronto-temporal cortex
}

\author{
H J Markowitsch, P Calabrese, J Liess, M Haupts, H F Durwen, W Gehlen
}

\begin{abstract}
An industrial manager had severe retrograde and variable but usually mild anterograde amnesia four years after a head injury. MRI showed damage of both temporal poles and the lateral portion of the right prefrontal cortex. The prefrontal and temporal cortical damage on the right side extended deeply into the white matter while the temporal cortical damage on the left side was much smaller. There was an additional left temporo-parietal lesion. The patient was of average intelligence. His attention, short term memory and learning ability were average or somewhat below average. His old memories were severely affected for the personal-episodic domain and less so for semantic remote memory abilities. Therefore an anatomical dissociation between anterograde and retrograde amnesia is possible at the anterior temporal regions, possibly interacting with the prefrontal cortex; these regions seem necessary for the retrieval of old episodic memories.
\end{abstract}

$(\mathfrak{F}$ Neurol Neurosurg Psychiatry 1993:56:988-992)

There are now descriptions of several cases of dissociation of anterograde and retrograde amnesia. ${ }^{1-11}$ In most of these cases the damage to the brain was the result of traumatic injury and can therefore be seen as resembling that described in several earlier reports in which concussions of the brain were followed by severe old memory disturbances. ${ }^{12-21}$ Last century a number of reports already dealt with the phenomenon of retrograde amnesia. ${ }^{22-24}$

Characteristic for most of the recent cases with dominant retrograde amnesia is the variability of their brain damage and the relatively better preserved semantic or priming-related remote memory compared with the severely affected episodic old memories. (Semantic memory refers to general knowledge about the world, for example, grammar, mathematical relations, chemical formulas; priming to "subconscious" knowledge or facilitated identification of information previously exposed to, and episodic memory to personal, temporally dated events.) In some case descriptions the retrograde amnesia related brain damage was identified in the junction zone of pons and mesencephalon, ${ }^{23}$ in the temporal, including the entorhinal cortex, ${ }^{6}$ in the temporo-parietal cortex,,$^{10125}$ in the temporo-polar cortex, ${ }^{78}$ and Kopelman ${ }^{26}$ favoured the prefrontal cortex as the principal target region implicated in the retrieval of remote memories. In his 1991 article, Kopelman ${ }^{27}$ specifically suggested that "dorsolateral frontal lesions (occurring in combination with limbic-diencephalic pathology) may account for an impoverished retrieval of retrograde memories."

\section{Case report}

A 45 year old male patient had had a severe traumatic brain injury four years earlier, caused by falling off a horse. He had been comatose for about six weeks. Before his accident the patient had been employed as a manager in a big company. He had been referred to us because of his persistent retrograde memory deficits. His present neurological status was examined with MRI and his neuropsychological status was tested during several sessions, over three days.

Most of the behavioural findings of the patient are compared with those of a normal subject of an age of 52 years, comparable intelligence, and a similar occupational position as the patient. For the retrograde memory tests additional comparisons were used. For the Autobiographical Memory Interview ${ }^{28}$ reference is made to the cut-off scores provided in that test. Results in the Famous Faces Test $^{29}$ are compared with those of a sample of control subjects tested by U Schuri (City Hospital Munich-Bogenhausen), and for the Famous names test we collected our own data by testing five normal subjects of comparable or lower educational background and age.

\section{NEURORADIOLOGICAL EXAMINATION}

MRI of his brain was performed using serial $\mathrm{T} 1$ and $\mathrm{T} 2$-weighted coronal and axial images (6 and $7 \mathrm{~mm}$ slices). Both temporal poles, with preference to the right hemisphere, were severely affected. Furthermore, the basal and lateral part of the right temporal lobe was damaged, sparing, however, the medial temporal lobe structures, including the hippocampal formation, on both sides (fig). Major brain damage was found in the fronto-basal cortex with preference to the right side. Additionally, an extensive corticosubcortical lesion was situated in the left temporo-parietal transition zone.

NEUROPSYCHOLOGICAL EXAMINATION

The neuropsychological tests and a summary 
Figure The principal brain damage in coronal and axial views. a-d:

Coronal $T_{2}$-weighted $M R I$ scans showing the main portions of the damage in the prefrontal and temporal lobes from anterior to posterior. ' $R$ ' and ' $L$ ' denote the left and right halves of the brain. $e$ : Magnification of the medial temporal area of the section shown in $d$ to demonstrate preservation of the hippocampal

formation. $f$, $g$ : Horizontal $T_{2}$-weighted MRI scans showing the main portions of the damage in the anterior and lateral temporal lobes.
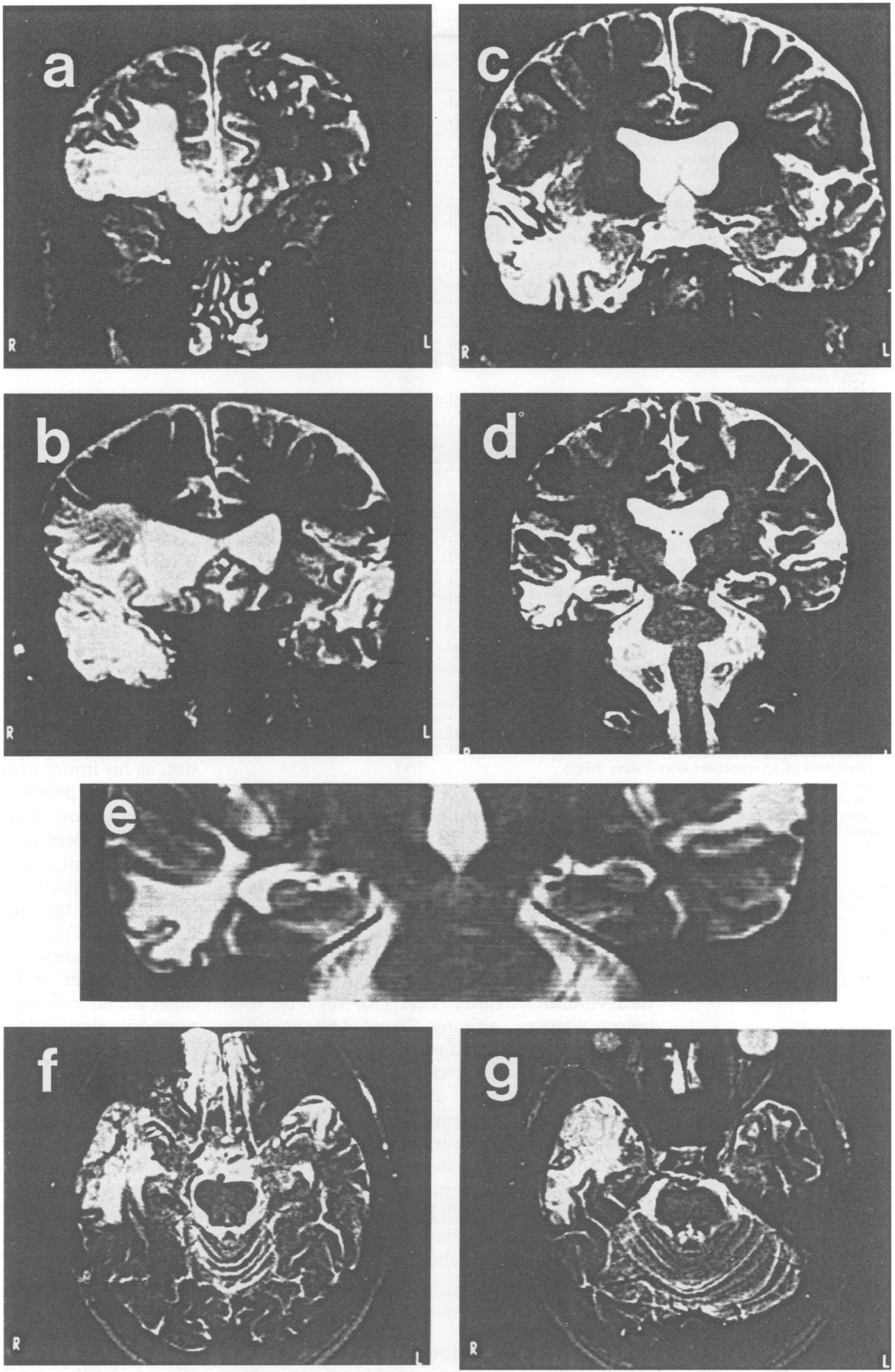

of the results are listed in table 1. They included tests of intelligence, attention, concentration, sensory and language functions, and various forms of memory tests. A number of these tests had been used and described in detail in a previous publication of a case with bilateral thalamic damage. ${ }^{30}$

The patient appeared to be alert, and interested. He made suggestions, was socially well-adjusted, and was able to interact in various ways with his environment. When instructed, he could remember to do something or to go to a certain place. In formal testing, he gained an IQ of 100 points, his attention, measured by three tests, was slightly below average. In the WechslerMemory-Scale- $R$ he received 85 points for the General-Memory-Index. The other values 
Table 1 Neuropsychological tests used

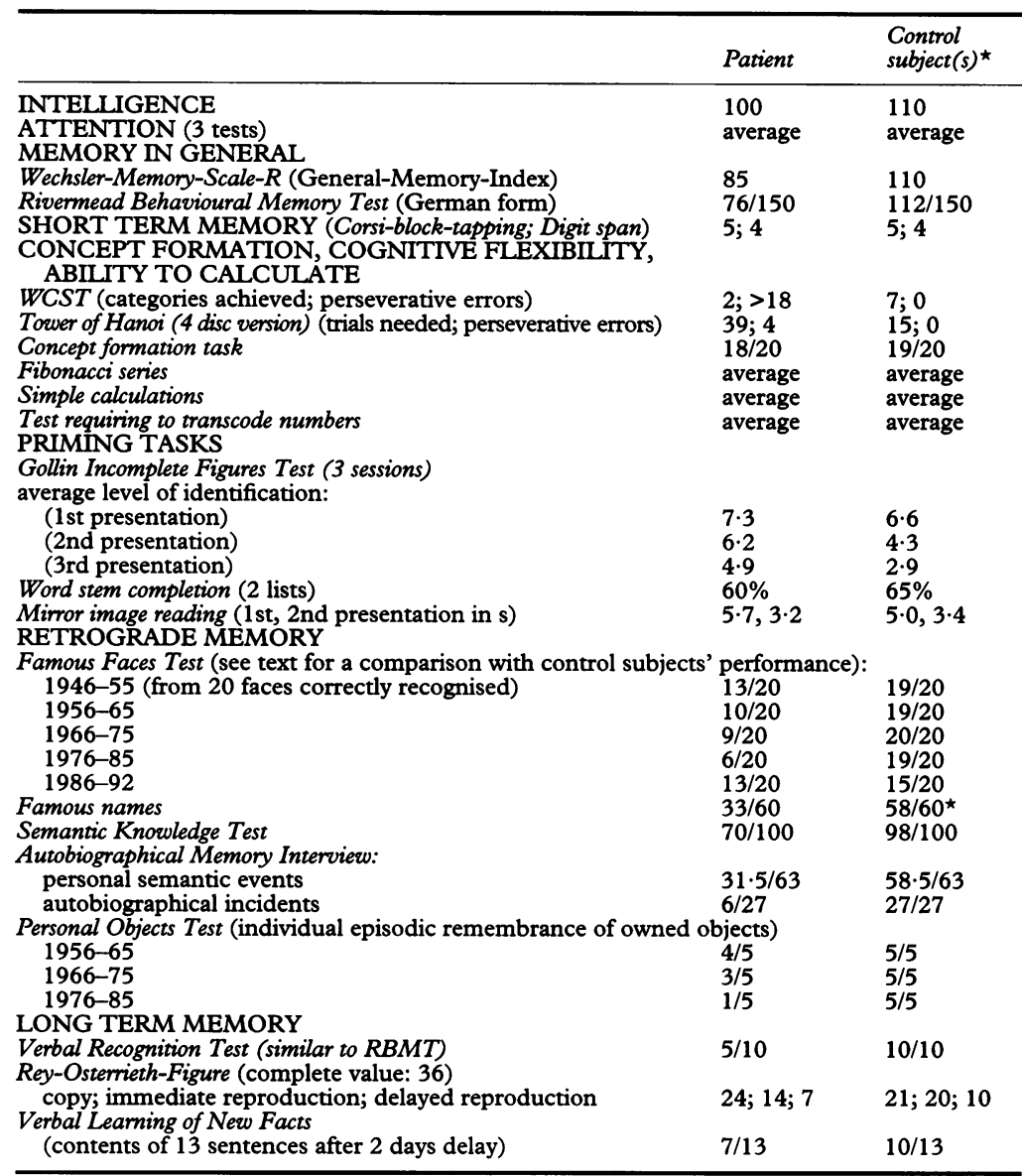

*For the Famous Names Test the patient's results were compared with those of a sample of five normal, age-matched control subjects (mean age $=51$ years) of comparable or lower educational level. Their mean value was $\mathbf{5 7 \cdot 8}$ points.
Table 2 Performance (points) of the patient and the control subject in the Autobiographical Memory Test

\begin{tabular}{lcll}
\hline Personal semantic events & Patient & $\begin{array}{l}\text { Control } \\
\text { subject }\end{array}$ & $\begin{array}{l}\text { Cut-off } \\
\text { scores [31]* }\end{array}$ \\
\hline Childhood & 6 & 18 & $<11$ \\
Early adulthood & 12 & 19.5 & $<14$ \\
Actual life & 13.5 & 21 & $<17$ \\
Sum (max.: 63 points) & 31.5 & 58.5 & $<47$ \\
Autobiographical incidents & & & \\
Childhood & 0 & 9 & $<3$ \\
Early adulthood & 0 & 9 & $<3$ \\
Actual life & 6 & 9 & $<5$ \\
Sum (max.: 27 points) & 6 & 27 & $<12$ \\
\hline
\end{tabular}

*The cut-off scores refer to "definitely abnormal" values; this means that the only not definitely abnormal (but "borderline") value was seen for the patient's recent autobiographical incidents, that is, for the current (post-injury) time period.

of people (actors, politicians, sportsmen, etc) from different time periods, and he or she has to produce the name of the respective subject. In scoring his (and the control subject's) performance, we also gave points when a correct answer was given after helping the subject by presenting initials or first names. The patient was rated poor for the intermediate time periods, but showed a gradient for remembering of famous faces from different decades (table 1). Compared with a sample of control subjects that were tested, the only values in a normal range were found for the first and the last time period tested. We attributed the normal remembrance for the last time period to his less affected anterograde memory abilities, as his injury occurred in 1987.

A similar performance was found for the Famous Names Test in which blocks of several names were given and the subject had to identify that of a person who was famous during a given epoch (multiple choice).

In a third measure, the Semantic General Knowledge Test (names of countries, currencies, cities, famous subjects, etc), the patient gained 70 out of 100 possible points which reflected an existing semantic or even priming memory, similar to the patient described by Damasio et al. ${ }^{31}$

Fourthly, the German language adaptation of the Autobiographical Memory Interview ${ }^{28}$ was given. The patient was clearly impaired in this test, but knew several overlearned personal and a few autobiographical facts. The only score that was better than "definitely abnormal" (according to the score by Kopelman et $a l^{28}$ ) was shown for his recent past, that is, the post-injury time period.

For the last test we collected from the patient's wife a number of personal objects which the patient had used during different time stages before and after his accident (Personal Objects Test). Of these we took five appropriate objects. For each of these five objects, verifiable and unequivocally dissociative events were expected. Scoring was carried out as follows: The first point was given when the object was correctly recognised as a personal belonging. Each further detail was given a point. For example, the patient had bought a pocket watch (1st point) for Christmas 1982 (2nd point) for a horrendous price (3rd point) at an exceptional hour of the day (4th point), and had later given it to his 
wife as a Christmas gift (5th point). Though there were some favoured objects among this collection, the patient recognised only those from the earliest (1956-65) and half of the second time period (1966-75) as belonging to him; for the last term before his brain damage (1975-86) he recognised only one object. For reported details, he gave four altogether, three, and one for the three time periods. In the period between his injury and the present he again recognised four objects; all the four he recognised were from the period after his brain damage, while the fifth, unrecognised, was from the epoch before his accident.

As an example of a possible dissociation between semantic and episodic memory, our patient when questioned about the location of Mount Kilimanjaro answered that it was situated in Tanzania. He did not remember that he had climbed its peak shortly before his accident. (This fact is particularly interesting as most people would be unable to name the country, and of the few who could, most would probably think of Kenya instead. In fact, it is situated in both countries, but the peak can only be reached from the Tanzanian side.) Another example is that he had been able to understand and to speak Italian on an advanced level before the trauma, but denied having any significant knowledge of the Italian language. As the principal examiner (PC) is a native Italian speaker, it was possible to test this statement by requesting the patient to follow some instructions given in Italian. The patient executed all verbal instructions correctly so that at least he understood this foreign language and could therefore respond to it at the level of priming.

Also his procedural memory remained largely intact giving a further example for dissociations among memory systems. The patient had been an avid car-driver since his youth and was able to drive before he was old enough to apply for a licence. After his accident he took some driving lessons and was still considered capable of managing a car.

\section{Discussion}

Our patient can be considered a typical example of a case with dominant, but not exclusive, retrograde amnesia. Furthermore, his retrograde memory disturbances are unequal with respect to true autobiographical and more impersonal, or semantic memory related knowledge. The formal test results on retrograde memory provide some support for this distinction (for example, considerable knowledge in the Semantic Knowledge Test, much better performance in the Autobiographical incidents as opposed to the Personal semantic events part of the Autobiographical Memory Interview), though not all results were clear-cut in this direction (for example, Famous Faces Test). Clear evidence for this dissociation comes from the everyday life examples (such as, knowledge of the geographical locus of Mount Kilimanjaro, no remembrance of having climbed it himself). The patient's mnestic functions were remarkably similar to those of Tulving's patient. $^{32}$

Our patient showed the possible relations between retrograde memory disturbances and certain brain foci. It is very unlikely that any medial temporal lobe damage existed which could have contributed to his deficits. His damage nevertheless was not restricted to one focus, but included a combination of bilateral temporal and right-sided frontal damage. Very similar to the case given by Kapur et al the temporal damage had its focus in the polar region and included some further, partly frontal, damage.

We conclude from the overall picture of his anatomical damage and from comparing his case with those described previously that the typical case with dominant retrograde amnesia can be characterised by a dominant (bilateral) temporo-polar focus with some adjacent, usually frontal-lobe, damage. This implies that the pathways interconnecting the anterior temporal cortex with the rest of the (association) cortex are severely disrupted. This may hold particularly to the uncinate fascicule, but also to pathways interconnecting the cingulate, retrosplenial, posterior temporal, and parietal cortex with the anterior temporal cortex. We cannot decide, to what degree the interruption of fibres relating the anterior temporal cortex to regions of amygdala and hippocampus and to thalamic nuclei are of importance. However, the findings by Iwai and Mishkin ${ }^{33}$ that the more anterior the temporal cortex is lesioned the more it affects memory, seems to receive new relevance, as do the recent findings by Sakai and Miyashita ${ }^{34}$ who suggested from their electrophysiological recordings in the anterior temporal cortex of monkeys that this region might be "activated in the retrieval process" of memorised events.

We also cannot specify the role of the frontal cortex in the context of retrograde amnesia. The role of this structure in timesequencing behaviour and in the ordering of information and therefore in relating it to context and to order information along the dimension time, seem mechanisms which will very likely contribute to a proper memorising of remote information. ${ }^{35-37}$

In most of the cases described as having dominant retrograde amnesia, the aetiology of the brain damage is a traumatic one, involving a severe, sudden concussion which affects the brain along its anterior-posterior axis. ${ }^{14}{ }^{16-19}$ Cases of amnesia pugilistica and amnesia after playing football may be similarly affected. ${ }^{121315202138}$

Descriptions of patients with totally intact anterograde amnesia, but severe retrograde amnesia are very rare and to date are not well documented. It therefore may be assumed that there is an interaction between both forms of amnesia, with the condition of more severe anterograde than retrograde memory defects being the most frequent, but not a necessary one. Especially under conditions of concussion- and coma-accompanied traumatic brain injury with an involvement of the 
temporal cortex (including its antero-lateral portion), the reverse deficit pattern, namely a severe retrograde and a mild anterograde memory impairment, may occur. It seems to be characteristic for these cases that the condition is stable so that there is little hope of (insight-related) improvement of remote memories.

We conclude from our present results and from those of previous studies that a severe interruption of the cortical fibre network interconnecting the anterior and posterior association areas of the cerebral cortex is a likely basis for remote memory impairments. A principal dissociation of anterograde and retrograde memory processing may therefore be possible on the neuroanatomical level. The medial portions of the temporal lobe including and surrounding the hippocampus may be necessary (though not sufficient) for the correct processing of new information, while the more lateral and anterior, largely neocortical portions may be necessary for the retrieval of memories.

We thank the patient and his wife for their cooperation and Professor L Heuser, Director of Radiology, Knappschaftskrankenhaus Bochum-Langendreer, for performing MRI. David Emmans deserves thanks for improving the English of the manuscript. The work reported here was supEnglish of the manuscript. The work reported here was sup-
ported by a grant of the German Research Council (DFG; Ma ported by

1 Andrews E, Poser CM, Kessler M. Retrograde amnesia for forty years. Cortex 1982;18:441-58.

2 Goldberg E, Antin SP, Bilder RM Jr, Gerstman LJ, Hughes JEO, Mattis SC. Retrograde amnesia: possible role of mesencephalic reticular activation on long-term memory. Science 1981;213:1392-4.

3 Goldberg E, Hughes JEO, Mattis S, Antin SP. Isolated retrograde amnesia: Different etiologies, same mecharetrograde amnesia: Different

4 Roman-Campos G, Poser CM, Wood FB. Persistent retrograde memory deficit after transient global amnesia. Cortex 1980;16:509-18.

5 Stuss DT, Guzman DA. Severe remote memory loss with minimal anterograde amnesia: A clinical note. Brain Cognit 1988;8:21-30

6 O'Connor M, Butters N, Miliotis P, Eslinger P, Cermak LS. The dissociation of anterograde and retrograde amnesia in a patient with herpes encephalitis. F Clin Exptal Neuropsychol 1992;14:159-178.

7 Kapur N, Young A, Bateman D, Kennedy P. Focal retrograde amnesia: a long term clinical and neuropsychologgrade amnesia: a long term clinical and

8 Kapur N, Ellison D, Smith MP, McLellan Burrows EH. Focal retrograde amnesia following bilateral temporal Focal retrograde amnesia following

9 Sloman SA, Hayman CAG, Ohta N, Law J, Tulving E. Forgetting in primed fragment completion. $\mathcal{f}$ Exptal Psychol: Learn Mem Cognit 1988;14:223-39.

10 Tulving E, Schacter DL, McLachlan DR, Moscovitch M Priming of semantic autobiographical knowledge: A case study of retrograde amnesia. Brain Cognit 1988; 8:3-20.

11 Tulving E, Hayman CAG, MacDonald CA. Long-lasting perceptual priming and semantic learning in amnesia: a case experiment. $尹$ Exptal Psychol: Learn Mem Cognit $1991 ; 17: 595-617$.

12 Blonstein JL, Clarke E. Further observations on the medical aspects of amateur boxing. Lancet 1957;i:362-4.

13 Critchley $M$. Medical aspects of boxing, particularly from a neurological standpoint. $B M \mathcal{F}$ 1957;1:357-66.

14 Fisher CM Concussion amnesia. Neurology 1966;16: 826-30.

15 Grahmann H, Ule G. Beitrag zur Kenntnis der chronischen cerebralen Krankheitsbilder bei Boxern. Psychiat Neurol 1957;134:261-83.

16 Russell WR. Amnesia following head injuries. Lancet 1935;ii:762-3.

17 Russell WR. The traumatic amnesias. Oxford: Oxford University Press, 1971.

18 Russell WR, Nathan PW. Traumatic amnesia. Brain 1946;69:280-300.

19 Symonds, C. Concussion and sequelae. Lancet 1962;i:1-5.

20 Yarnell PR, Lynch S. Retrograde memory immediately after concussion. Lancet 1970;i:863-4.

21 Yarnell PR, Lynch S. The "ding": Amnestic states in football trauma. Neurology 1973;23:196-7.

22 Burnham WH. Retroactive amnesia: illustrative cases and a tentative explanation. Am $\mathcal{F}$ Psychol 1903;14:382-96.

23 Dana CL. The study of a case of amnesia or "double consciousness". Psychol Rev 1894;1:570-80.

24 Markowitsch HI. Intellectual functions of the brain. An historical perspective. Toronto: Hogrefe and Huber, 1992.

25 De Renzi E. Focal retrograde amnesia: a PET study. Conference: "Anatomy of amnesia", Manchester 10-12, 1992.

26 Kopelman MD. Remote and autobiographical memory, temporal context memory and frontal atrophy in Korsakoff and Alzheimer patients. Neuropsychologia 1989;27:437-60.

27 Kopelman MD. Frontal dysfunction and memory deficits in the alcoholic Korsakoff syndrome and Alzheimer-type dementia. Brain 1991;114:117-137.

28 Kopelman MD, Wilson BA, Baddeley AD. The autobiographical memory interview: A new assessment of autobiographical and personal semantic memory in amnesic patients. $\mathcal{f}$ Clin Exptal Neuropsychol 1989;11:724-44.

29 Warringtron EK. Recognition memory test. Windsor, UK NFER-Nelson, 1984

30 Markowitsch HJ, von Cramon DY, Schuri U. The mnestic performance profile of a bilateral diencephalic damaged case with preserved intelligence and severe aged case with preserved intelligence and severe (in press).

31 Damasio AR, Tranel D. Knowing that "Colorado" goes with "Denver" does not imply knowledge that "Denver" is in "Colorado". Behav Brain Res 1990;40 193-200.

32 Tulving E. Remembering and knowing the past. Am Scient 1989;77:361-7

33 Iwai E, Mishkin M. Two visual foci in the temporal lobe of monkey. fapan-United States foint Seminar on Neurophysiological Basis of Learning, 1969.

34 Sakai K, Miyashita Y. Neural organization for the longterm memory of paired associates. Nature 1992, 354:152-155.

35 Fuster JQ. The prefrontal cortex. Anatomy, physiology and neuropsychology, 2nd ed. New York: Raven Press, 1989.

36 Markowitsch HI. Anatomical and functional organization of the primate prefrontal cortical system. In: Steklis of the primate prefrontal cortical system. In: Stekli Neurosciences. New York: Alan R. Liss, 1988;99-153.

37 Stuss DT, Benson DF. The frontal lobes. New York: Raven Press, 1986.

38 Markowitsch HJ. Neuropsychologie des Gedächtnisses. Göttingen: Hogrefe, 1992. 